\title{
Comparison of blood and milk non-specific immune parameters in heifers after calving in relation to udder health
}

\author{
Renata PICCININI, Enrica BINDA, Michela BELOTTI, Giuseppe CASIRANI, \\ Alfonso ZECCONI* \\ Università degli Studi di Milano, Dipartimento di Patologia Animale, Igiene e Sanità Pubblica \\ Veterinaria, Sezione di Malattie Infettive, via Celoria 10, 20133 Milano, Italy
}

(Received 4 October 2004; accepted 22 February 2005)

\begin{abstract}
A practical protocol to study udder immune status in field conditions was planned with the aim to assess different non-specific immune parameters in milk samples from dairy heifers during the periparturient period. Five herds located in northern Italy were selected and overall 39 heifers were enrolled in the trial. Milk samples were taken at 7, 14, 21, 28, 45, 60, and 75 days after calving. The parameters assessed were $\mathrm{N}$-acetyl- $\beta$-glucosaminidase (NAGase), lysozyme, respiratory burst (RB), somatic cell counts (SCC) and serum protein profile. SCC and NAGase were higher in the first sampling after calving, while lysozyme showed large variations during the observation period without a definite trend. The levels of RB observed in the first two weeks after calving, even if lower, were not statistically different from the values observed in samples taken over the following weeks. This study confirmed that the levels of immune components in milk are different from what is observed at blood level in the same cow. A significant decrease in RB in milk polymorphonuclear leukocytes (PMN) post-calving was not observed; milk PMN from healthy cows showed low RB levels, while the values from infected quarters were significantly higher. Significant differences between healthy and infected animals were also observed for milk NAG, lactoglobulin and albumin. These data suggest that udder immune response could be influenced both by the cow immune status and by external factors such as pathogens and management. Therefore, the reduction in immune defences, particularly in heifers, is not unavoidable and methods to boost PMN activity should be explored.
\end{abstract}

heifers / periparturient period / blood milk / non-specific immunity

\section{INTRODUCTION}

The periparturient period is one of the most important and critical periods. It has been demonstrated that around calving some impairment of immune defences can be observed [8, 12]. This impairment increases the frequency of reproductive, production and udder diseases, as shown experimentally and under field conditions [1, 4, 5, 7, 29].

Most of the information available on cow immune defences are based on blood parameters, while data on milk immune defences are fewer, even if their number is increasing [20, 21, 25, 27].

\footnotetext{
* Corresponding author: alfonso.zecconi@unimi.it
} 
In order to evaluate the possibility to develop a practical protocol to study the immune status of dairy cows under field conditions, a study was planned to assess several non-specific immune parameters in blood and milk from dairy heifers during the periparturient period. A detailed description of the results on blood parameters has already been published in this journal [23]. This paper reports the results concerning milk immune parameters, and compares the pattern of the non-specific immune parameters measured contemporarily in blood and milk in relation to the health status of the mammary gland.

\section{MATERIALS AND METHODS}

\subsection{Animals and samplings}

Five herds located in northern Italy, were selected. The herds can be considered as representative of Italian dairy herds, all of them are free-stall herds, herd size is in the range 80-350 Holstein cows; total mix ratio, dry-cow therapy and post-dip are regularly applied. Overall 39 heifers, free from clinical diseases, were enrolled in the trial ( 7 from herd A, 12 from herd B, 7 from herd C, 4 from herd D, 9 from herd E). All the pregnant heifers with an expected calving date between January and April were enrolled in the study. This period was selected to reduce the influence of the climate (i.e. a hot and humid climate, heavy rain) on immune parameters. Indeed, in the Italian environment late winter is the most stable period, with a low rain rate and temperature between 0 and $10{ }^{\circ} \mathrm{C}$.

Quarter milk samples (QMS) were collected before milking by an aseptic procedure starting $7 \pm 1$ days after calving, then at $14 \pm 1,21 \pm 1,28 \pm 1,45 \pm 1,60 \pm 1$, and $75 \pm$ 1 days after calving. Blood samples were taken at the same intervals as milk samples.

\subsection{Milk bacteriological analysis}

At the laboratory, an aliquot $(0.01 \mathrm{~mL})$ of each QMS was spread on blood agar plate. The colonies were isolated and identified by proper methods according to the National Mastitis Council [17]. Somatic cells were counted on a Bentley Somacount 150 (Bentley, USA). The quarter status was defined following the scheme described by Pyorala [24]. Samples with SCC $\geq 200000$ cells $/ \mathrm{mL}$ were defined as positive for intramammary infection (IMI); a bacteriologically positive sample with SCC $<200000$ cells/mL as latent IMI; a bacteriologically negative sample was defined as healthy if SCC were $<200000$ cells $/ \mathrm{mL}$.

\subsection{Serum, whey and cell isolation}

Whey was obtained from skimmed milk by centrifugation at $60000 \times g$ for $30 \mathrm{~min}$ at $4{ }^{\circ} \mathrm{C}$, while serum was obtained from centrifugation of the blood at $1500 \times g$ for $15 \mathrm{~min}$ at room temperature. Then the whey and serum were aliquoted in $1500 \mu \mathrm{L}$ tubes and immediately frozen at $-80^{\circ} \mathrm{C}$ for the enzyme analyses. These analyses were performed in a single session for each enzyme, at the end of the follow-up period.

Polymorphonuclear leukocytes (PMN) were isolated from milk by density gradient separation after centrifugation at $500 \times g$ for 15 min at $4{ }^{\circ} \mathrm{C}$ on Ficoll-Paque Plus (AmeshamBiosciences, Sweden), following the procedure described by Carlson and Kaneko [2] and immediately delivered for the respiratory burst assay. The same procedure was followed for the isolation of blood PMN, applying blood hypotonic lysis instead of centrifugation.

\subsection{Respiratory burst}

Respiratory burst (RB) was assessed by luminol-enhanced chemiluminescence. The assay was performed adding $0.7 \times 10^{6}$ of viable $\mathrm{PMN} / \mathrm{mL}$ to two wells of a microplate; in one well, PMN were stimulated with phorbol myristate acetate, PMA (SigmaAldrich, USA) at a concentration of $1 \mu \mathrm{g} / \mathrm{mL}$, while PMN in the other well were not stimulated (control). After injecting $40 \mu \mathrm{L}$ of $0.3 \mathrm{mM}$ luminol (Sigma-Aldrich, USA), 
the chemiluminescence produced was automatically recorded for $30 \mathrm{~min}$ on a microplate luminometer (Luminoskan Ascent, Themolabsystem, Finland) and the total chemiluminescence emission, expressed in $\mathrm{mV}$, was calculated.

\subsection{Biochemical assays}

Lysozyme was assessed in duplicate by the procedure described by Metcalf et al. [16]. The method is based on the lysis of $\beta$ 1,4 glucosidic linkages between $\mathrm{N}$-acetylmuramic acid and $\mathrm{N}$-acetylglucosamine in the mucopeptide cell wall structure of Micrococcus lysodeicticus. The lyses of bacteria were measured by changes in optical density at $450 \mathrm{~nm}$ after $2 \mathrm{~min}$ on a microplate spectrophotometer (Spectramax 340, Molecular Devices, USA). The concentration of unknown samples, in $\mu \mathrm{g} / \mathrm{mL}$, was calculated by a standard curve obtained by adding a standard amount of lysozyme in each plate.

$\mathrm{N}$-Acetyl- $\beta$-glucosaminidase (NAG) was assessed in duplicate by the procedure described by Kitchen et al. [10], and expressed as units defined as pmol of 4-methylumbelliferon released per min at $25^{\circ} \mathrm{C}$ catalysed by $1 \mu \mathrm{L}$ of milk, on a microplate fluorimeter at 355 ex and 460 em (Ascent, ThemoLabsystem, Finland).

\subsection{Serum protein electrophoresis}

Whey proteins were assessed by agarose gel electrophoresis with Hydragel 15 HR (Sebia, France), a kit that allows a higher resolution of electrophoresis in comparison with the one normally applied to serum proteins. This kit is intended for the separation of serum and whey proteins on an automated multiparametric agarose gel electrophoresis system (Hydrasis, Sebia, France). The gels were analysed by a densitometer and dedicated software (Phoresis, Sebia, France). Protein standards (albumin, $\alpha$ - and $\beta$-globulins, and $\gamma$-globulins) were added as a reference for the densitometer analysis. Serum proteins were assessed by the same procedure and instrument applying the standard kit for blood serum proteins (Hydragel 30, Sebia, France).

Total proteins (TP) were assessed in duplicate by a bicinchoninic acid assay [26] with a commercial kit (BCA Protein Assay Kit, Piece, USA) on a microplate spectrophotometer at $562 \mathrm{~nm}$ (Spectramax 340, Molecular Devices, USA).

\subsection{Statistical analysis}

The data were collected in a database, and the differences among sampling times were analysed by the general linear model for repeated measures procedure on SPSS 11.5 [28]. The between-subject factor was represented by herd (5 levels) and the within-subject factor was represented by sampling time (7 levels) and the model applied was a full factorial, with polynomial contrasts for the within-subject factor. In order to compare the differences in immune parameters between healthy and infected cows, a general linear model procedure on SAS software [26] was applied. The model applied was a full factorial, and included herd (5 levels), health status (2 levels, healthy and positive) and sampling (7 levels), and the appropriate error terms for within- and between-subject factors as suggested by Hatcher and Stepanski [6] were applied. The cows were classified as healthy if all four quarters were healthy and positive if at least one quarter was IMI positive.

\section{RESULTS}

Overall, the frequency of IMI at the quarter level was higher at the first sampling after calving except for herd D (Tab. I). The frequency of negative samples, after the first sampling, was in the range 60-79\%, while latent infections had a low frequency, in the range 11-22\%. Some differences can be observed among herds. Indeed, herd E showed overall the highest frequency of 
Table I. Distribution of quarter health status among herds and samplings (\%). Quarter status is defined according to [22].

\begin{tabular}{|c|c|c|c|c|c|c|c|c|c|}
\hline \multirow[t]{2}{*}{ Herd } & \multirow[t]{2}{*}{ Status } & \multicolumn{8}{|c|}{ Samplings } \\
\hline & & 7 & 14 & 21 & 28 & 45 & 60 & 75 & Total \\
\hline \multirow[t]{3}{*}{ A } & Negative & 42.86 & 85.71 & 64.29 & 35.71 & 50.00 & 40.00 & 80.00 & 56.98 \\
\hline & Latent & 0 & 14.29 & 14.29 & 35.71 & 10.00 & 30.00 & 0 & 15.12 \\
\hline & Positive & 57.14 & 0 & 21.42 & 28.57 & 40.00 & 30.00 & 20.00 & 27.90 \\
\hline \multirow[t]{3}{*}{ B } & Negative & 26.09 & 50.00 & 63.64 & 68.18 & 45.00 & 75.00 & 65.00 & 55.70 \\
\hline & Latent & 21.74 & 27.27 & 18.18 & 18.18 & 35.00 & 5.00 & 20.00 & 20.81 \\
\hline & Positive & 52.17 & 22.73 & 18.18 & 13.64 & 20.00 & 20.00 & 15.00 & 23.49 \\
\hline \multirow[t]{3}{*}{$\mathrm{C}$} & Negative & 50.00 & 57.14 & 64.29 & 92.86 & 78.57 & 78.57 & 85.71 & 72.45 \\
\hline & Latent & 7.14 & 14.29 & 14.29 & 0 & 21.43 & 21.43 & 14.29 & 13.27 \\
\hline & Positive & 42.86 & 28.57 & 21.42 & 7.14 & 0 & 0 & 0 & 14.28 \\
\hline \multirow[t]{3}{*}{ D } & Negative & 87.50 & 62.50 & 66.67 & 50.00 & 62.50 & 62.50 & 75.00 & 66.67 \\
\hline & Latent & 12.50 & 25.00 & 16.67 & 37.50 & 12.50 & 12.50 & 25.00 & 20.37 \\
\hline & Positive & 0 & 12.50 & 16.66 & 12.50 & 25.00 & 25.00 & 0 & 12.96 \\
\hline \multirow[t]{3}{*}{$\mathrm{E}$} & Negative & 43.75 & 86.67 & 82.35 & 88.88 & 66.67 & 61.11 & 88.89 & 74.16 \\
\hline & Latent & 6.25 & 13.33 & 11.76 & 5.56 & 22.22 & 22.22 & 0 & 11.67 \\
\hline & Positive & 50.00 & 0 & 5.89 & 5.56 & 11.11 & 16.67 & 11.11 & 14.17 \\
\hline \multirow[t]{3}{*}{ Total } & Negative & 44.00 & 67.12 & 68.49 & 69.73 & 60.00 & 65.72 & 78.57 & 64.70 \\
\hline & Latent & 10.67 & 19.18 & 15.07 & 17.11 & 22.86 & 17.14 & 11.43 & 16.17 \\
\hline & Positive & 45.33 & 13.70 & 16.44 & 13.16 & 17.14 & 17.14 & 10.00 & 19.13 \\
\hline
\end{tabular}

healthy quarters during the whole followup period, while herd A showed the highest frequency of IMI in all samplings. Among the 100 bacteriological positive samples, $45 \%$ were coagulase negative Staphylococci, $39 \%$ environmental streptococci $14 \%$ Staphylococcus aureus and $2 \%$ other species.

Table II reports the mean values observed for the different milk parameters during the follow-up period. The first sampling after calving was the highest for SCC, NAGase $(\mathrm{NAG})$ and $\gamma$-globulins $(\gamma \mathrm{G})$. Serum albumin (ALB) and lactoferrin (LF) were rather stable; lactoglobulin (LG) and respiratory burst (RB) values were higher after the first sampling, whereas lactoalbumin (LA) showed an increasing trend as the days in milk (DIM) increased. The statistical analysis for repeated measurements (Tab. III) confirmed that the mean values at the first sampling for NAG, SCC, LG and $\gamma \mathrm{G}$ were statistically different from the values observed in the following samplings. Lactoalbumin showed significantly higher values in samples taken from 28 DIM until the end of the follow-up period, when compared with the samples taken in the first three weeks of lactation.

\subsection{Factors influencing non-specific immune parameters in milk}

The analysis of the influence of the different factors on milk immune parameters (Tab. IV) showed that the interaction of herd and sampling was significant for all immune parameters considered, out of RB. The herd was statistically significant only for ALB and $\gamma \mathrm{G}$, while sampling was statistically significant for all parameters except for lysozyme, ALB and LF. 
Table II. Mean values $( \pm$ SE) for the different milk immune parameters assessed from 7 to 75 days after calving.

\begin{tabular}{lccccccc}
\hline Milk parameter & \multicolumn{7}{c}{ Days from calving } \\
\cline { 2 - 9 } & 7 & 14 & 21 & 28 & 45 & 60 & 75 \\
\hline Lysozyme $(\mu \mathrm{g} / \mathrm{mL})$ & $0.21 \pm 0.11$ & $0.05 \pm 0.05$ & $0.11 \pm 0.06$ & $0.13 \pm 0.08$ & $0.21 \pm 0.15$ & $0.18 \pm 0.18$ & $0.22 \pm 0.16$ \\
NAGase (units) & $108.0 \pm 7.9$ & $71.9 \pm 4.6$ & $53.3 \pm 3.8$ & $44.1 \pm 2.5$ & $44.2 \pm 3.4$ & $31.2 \pm 3.3$ & $33.4 \pm 3.8$ \\
Serum albumin (\%) & $6.5 \pm 0.2$ & $6.7 \pm 0.2$ & $6.8 \pm 0.3$ & $6.9 \pm 0.3$ & $6.7 \pm 0.3$ & $6.2 \pm 0.2$ & $6.4 \pm 0.3$ \\
Lactoglobulin (\%) & $42.3 \pm 0.9$ & $45.6 \pm 0.6$ & $46.5 \pm 0.6$ & $45.6 \pm 0.5$ & $45.3 \pm 0.6$ & $46.2 \pm 0.5$ & $45.9 \pm 0.7$ \\
Lactoalbumin (\%) & $25.6 \pm 0.5$ & $26.4 \pm 0.4$ & $26.4 \pm 0.4$ & $28.3 \pm 0.5$ & $30.2 \pm 0.5$ & $31.7 \pm 0.4$ & $31.5 \pm 0.9$ \\
Lactoferrin $(\%)$ & $3.21 \pm 0.3$ & $3.14 \pm 0.2$ & $3.19 \pm 0.2$ & $3.25 \pm 0.1$ & $3.21 \pm 0.1$ & $2.89 \pm 0.1$ & $2.63 \pm 0.2$ \\
$\gamma$-globulin $(\%)$ & $18.77 \pm 0.9$ & $15.12 \pm 0.4$ & $13.9 \pm 0.4$ & $12.96 \pm 0.4$ & $11.55 \pm 0.4$ & $10.14 \pm 0.4$ & $11.04 \pm 1.0$ \\
Oxidative burst $(\mathrm{mV})$ & $4.01 \pm 1.0$ & $4.95 \pm 1.3$ & $3.94 \pm 1.3$ & $3.43 \pm 1.1$ & $5.66 \pm 2.2$ & $5.37 \pm 1.9$ & $4.43 \pm 2.2$ \\
SCC (log 10 cell/mL) & $4.90 \pm 0.1$ & $4.14 \pm 0.1$ & $4.28 \pm 0.1$ & $4.07 \pm 0.1$ & $3.93 \pm 0.1$ & $4.03 \pm 0.1$ & $3.96 \pm 0.2$ \\
\hline
\end{tabular}

Table III. Presence of a significant difference $(P<0.05)$ among samples by the general linear model for repeated measurements of milk parameters.

\begin{tabular}{|c|c|c|c|c|c|c|}
\hline \multirow{2}{*}{$\begin{array}{l}\text { Days from } \\
\text { calving }\end{array}$} & \multicolumn{6}{|c|}{ Days from calving } \\
\hline & 14 & 21 & 28 & 45 & 60 & 75 \\
\hline \multirow[t]{5}{*}{7} & $\mathrm{NAG}^{\mathrm{a}, \mathrm{b}}$ & NAG & NAG & NAG & NAG & NAG \\
\hline & LG & LG & LG & LG & LG & LG \\
\hline & & & LA & LA & LA & LA \\
\hline & $\gamma \mathrm{G}$ & $\gamma \mathrm{G}$ & $\gamma \mathrm{G}$ & $\gamma \mathrm{G}$ & $\gamma \mathrm{G}$ & $\gamma \mathrm{G}$ \\
\hline & $\mathrm{SCC}$ & SCC & $\mathrm{SCC}$ & SCC & SCC & SCC \\
\hline \multirow[t]{3}{*}{14} & & NAG & NAG & NAG & NAG & NAG \\
\hline & & & LA & LA & LA & LA \\
\hline & & $\gamma \mathrm{G}$ & $\gamma \mathrm{G}$ & $\gamma \mathrm{G}$ & $\gamma \mathrm{G}$ & $\gamma \mathrm{G}$ \\
\hline \multirow[t]{5}{*}{21} & & & & & NAG & NAG \\
\hline & & & & LG & LG & \\
\hline & & & LA & LA & LA & LA \\
\hline & & & & & $\gamma \mathrm{G}$ & $\gamma \mathrm{G}$ \\
\hline & & & SCC & SCC & & SCC \\
\hline \multirow[t]{3}{*}{28} & & & & & & NAG \\
\hline & & & & & LA & LA \\
\hline & & & & & $\gamma \mathrm{G}$ & $\gamma \mathrm{G}$ \\
\hline \multirow[t]{3}{*}{45} & & & & & NAG & NAG \\
\hline & & & & & LA & LA \\
\hline & & & & & & $\mathrm{RB}$ \\
\hline 60 & & & & & & $\mathrm{RB}$ \\
\hline
\end{tabular}

a The presence of parameter acronym in the cell shows the presence of a significant difference between the samplings indicated by the respective row and column headings.

b NAGase: N-acetyl- $\beta$-glucosaminidase, ALB: serum Albumin, LA: lactoalbumin, LG: lactoglobulin, $\gamma \mathrm{G}$ : gamma-globulin, LF: lactoferrin, SCC: somatic cell counts, RB: respiratory burst. 

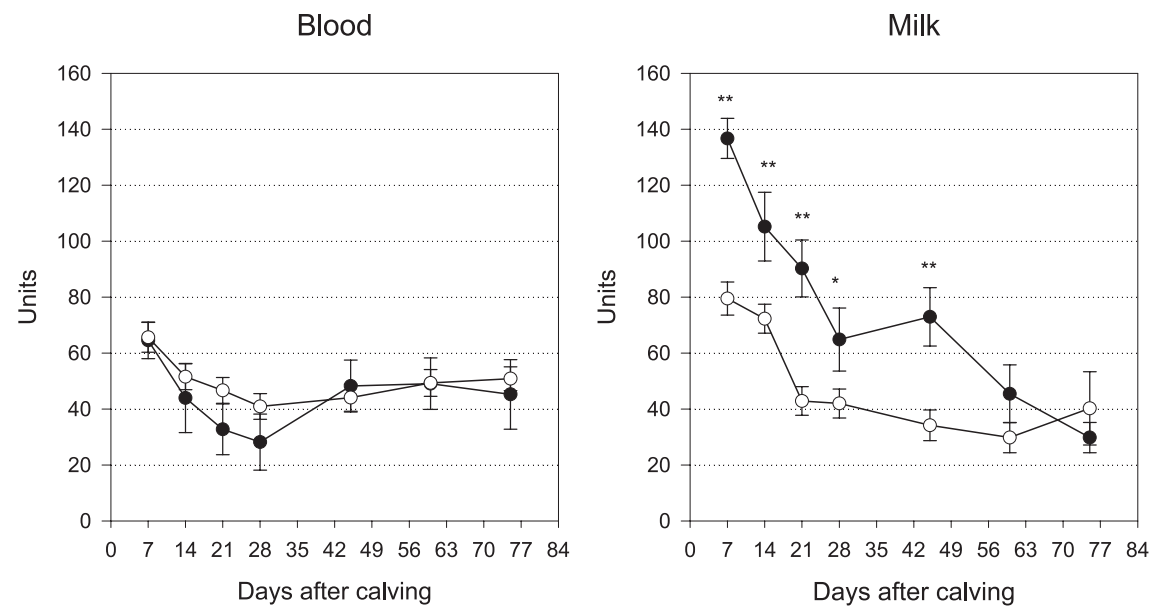

Figure 1. Distribution of the mean \pm SE of NAGase in blood and milk, by mammary gland health status ( $\bullet$ IMI; $\bigcirc$ : healthy) during the follow-up period. Stars on sampling mean a statistical significant difference among negative and positive milk samples $(* P<0.10 ; * * P<0.05)$.

Table IV. Summary of analysis of variance with the general linear model for repeated measurements for the milk immune parameters considered.

\begin{tabular}{lccc}
\hline Parameter & \multicolumn{2}{c}{ Within-subject factors } & Between-subject factor \\
\cline { 2 - 4 } & Sampling & Sampling $\times$ Herd & Herd \\
\hline Lysozyme & n.s. & 0.068 & n.s. \\
NAGase & 0.000 & 0.001 & n.s. \\
Albumin & n.s. & 0.003 & 0.047 \\
Lactoglobulin & 0.005 & 0.000 & n.s. \\
Lactoalbumin & 0.000 & 0.000 & n.s. \\
Lactoferrin & n.s. & 0.009 & n.s. \\
$\gamma$-globulin & 0.000 & 0.002 & 0.057 \\
Respiratory burst & 0.071 & n.s. & n.s. \\
SCC & 0.000 & 0.000 & n.s. \\
\hline
\end{tabular}

${ }^{a}$ Not significant $(P>0.05)$.

\subsection{Blood and milk comparison}

The most challenging results were observed when blood and milk immune parameters were compared in healthy and IMI animals. Latent infections were not included in the analysis, because of their low frequency.

NAGase in blood showed similar patterns in both samples taken from healthy and unhealthy cows, with a decrease in the first month of lactation (Fig. 1). A different pattern was observed in milk. Indeed, milk samples showed an overall decline in NAGase activity as lactation advanced. However, mean levels in infected quarters showed values significantly higher than those in negative ones. In the second and third months of lactation, negative quarters showed rather stable values around 40 units, while in IMI the quarters declined progressively, even if the 

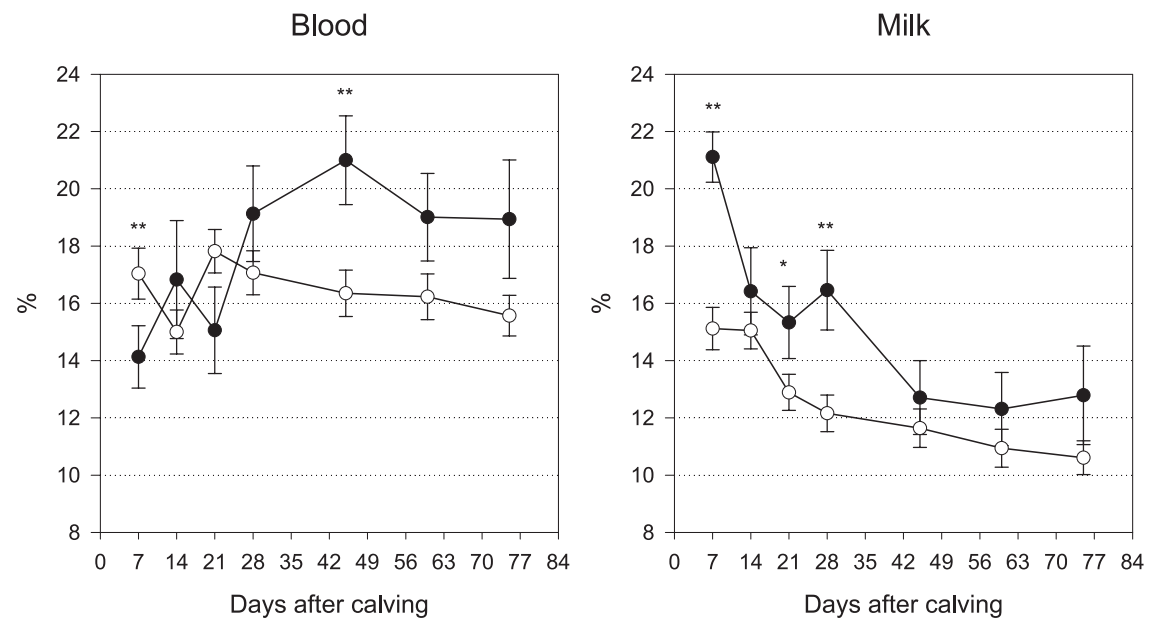

Figure 2. Distribution of the mean \pm SE of $\gamma$-globulins in blood and milk, by mammary gland health status (•: IMI; $\bigcirc$ : healthy) during the follow-up period. Stars on sampling mean a statistical significant difference among negative and positive blood and milk samples $(* P<0.10$; ** $P<0.05)$.

levels were higher than in the negative quarters, until the last sample.

Lysozyme showed a very large variation in blood, when stratified by the mammary gland health status, while milk lysozyme showed very low mean levels independently of sampling and udder health (data not shown).

Gamma-globulins showed a completely different pattern between IMI and negative quarters both in blood and milk (Fig. 2). Blood $\gamma \mathrm{G}$ was significantly lower at first sampling in IMI quarters, increasing significantly at 45 DIM, when compared with negative quarters. In milk, $\gamma \mathrm{G}$ were significantly higher in IMI quarters in comparison to negative quarters, and the values declined in both cases from 7 to 45 DIM.

Milk PMN respiratory burst levels were significantly higher in IMI samples when compared with healthy ones, throughout the follow-up period (Fig. 3). In the first three weeks after calving, RB in blood PMN showed levels lower than in the following samplings, both in healthy and IMI cows.

Milk serum albumin (Fig. 4) showed a different pattern from the other parameters considered. The mean values were similar during the follow-up period in both healthy and IMI quarters, except for samples taken at 21 and 28 DIM when the IMI quarters showed significantly higher levels of ALB in comparison with the healthy quarters. This pattern was the opposite of the one observed in blood, where infected cows showed lower ALB concentration in comparison with healthy cows, with a significant difference at $28 \mathrm{~d}$ (Fig. 4).

Figure 5 reports the pattern of LG in milk. During the first month of lactation IMI quarters showed significant lower levels in comparison with negative quarters. In blood, globulins showed lower values in the first month of lactation, both in IMI and negative cows, in comparison with the remaining part of the follow-up period.

\section{DISCUSSION}

The mammary gland is a very peculiar organ; indeed, while its main role is to produce milk, one of the safest foods in nature, it is open to the external environment and 
Blood

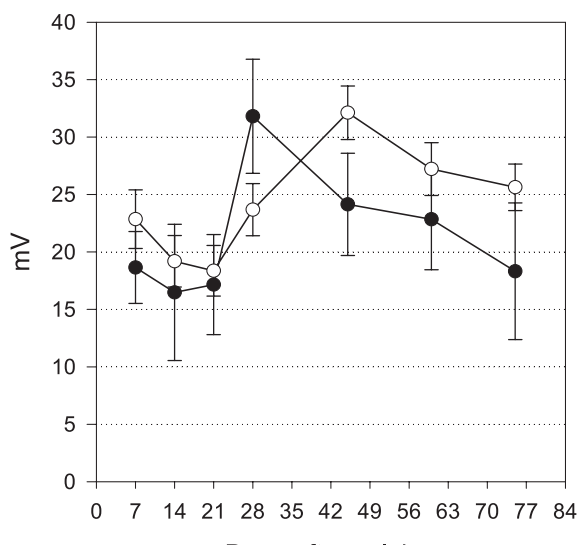

Milk

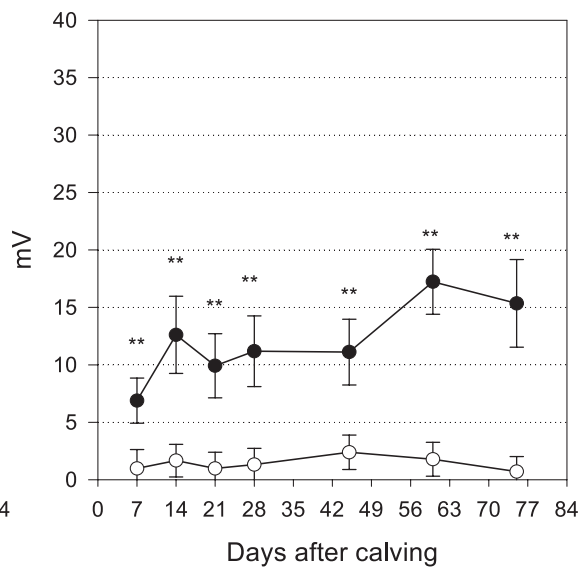

Figure 3. Distribution of the mean \pm SE of respiratory burst in blood and milk, by mammary gland health status (•: IMI; $\bigcirc$ : healthy) during the follow-up period. Stars on sampling mean a statistical significant difference among negative and positive milk samples $\left(* P<0.10\right.$; $\left.{ }^{*} P<0.05\right)$.
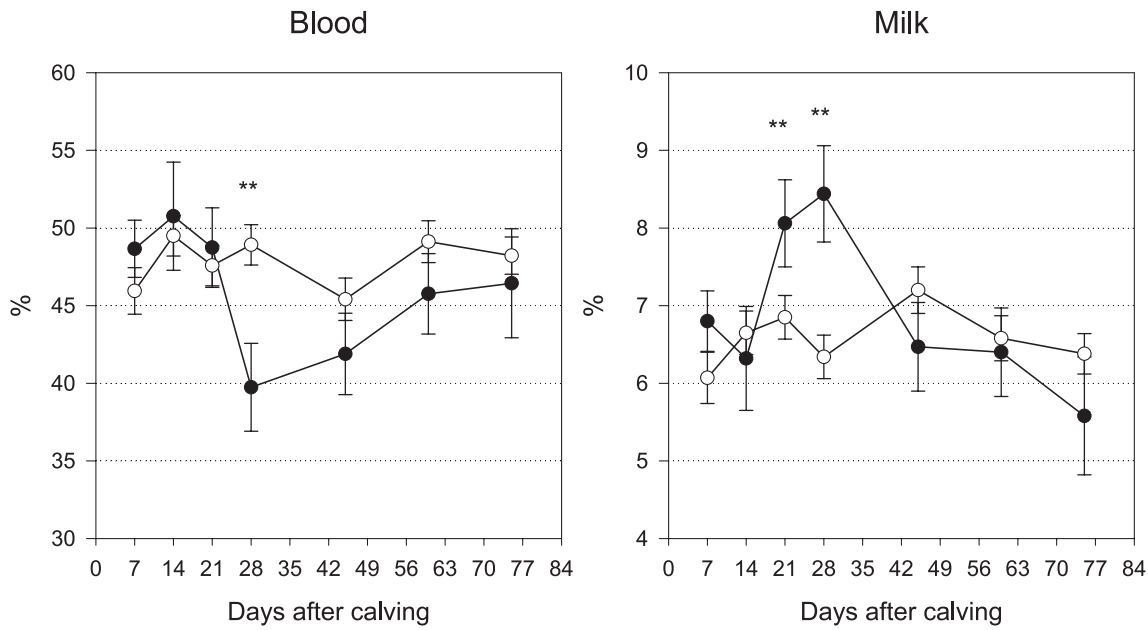

Figure 4. Distribution of the mean $\pm S E$ of albumin in blood and milk, by mammary gland health status ( $\bullet$ : IMI; $\bigcirc$ : healthy) during the follow-up period. Stars on sampling mean a statistical significant difference among negative and positive blood and milk samples $(* P<0.10 ; * * P<0.05)$.

therefore exposed to pathogens. This explains the scientific and practical interest in understanding mammary gland immune defences $[3,29]$.
In this field study, non-specific humoral defences, such as LF and milk $\gamma \mathrm{G}$, showed higher mean values in the first week after calving, when compared with the following 
Blood

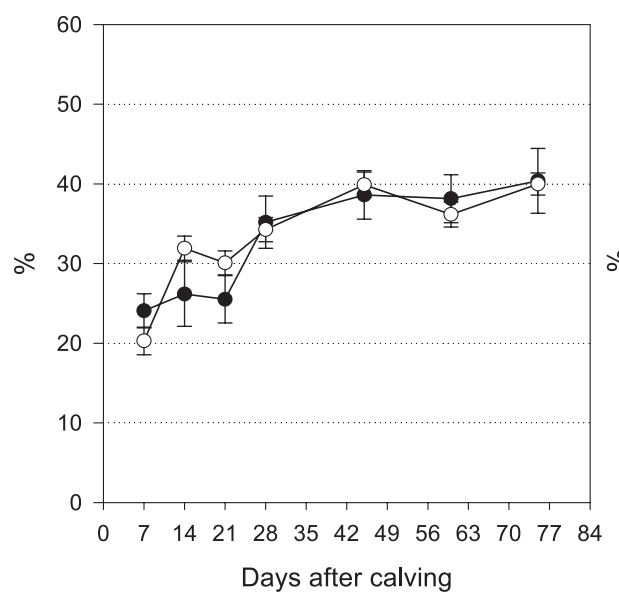

Milk

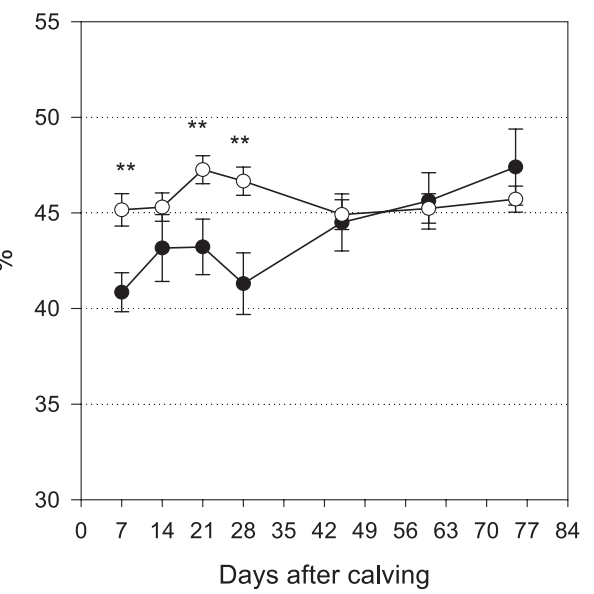

Figure 5. Distribution of the mean \pm SE of globulins $(\alpha+\beta)$ in blood and lactoglobulin in milk, by mammary gland health status ( $\bullet$ : IMI; $\bigcirc$ : healthy) during the follow-up period. Stars on sampling mean a statistical significant difference among negative and positive milk samples $(* P<0.10$; $* * P<0.05)$

samplings. However, the differences were statistically significant only for $\gamma \mathrm{G}$, as expected, being that this latter component is one of the most important milk constituents for newborn calves.

SCC and consequently milk NAGase, a lysosomial enzyme, were higher in the first sampling after calving, as expected [10, 24]. The levels of RB in milk PMN observed in the first two weeks after calving, even if lower, were not statistically different from the values observed in samples taken over the following weeks. This result was not in agreement with the results observed in blood, where a significant decrease was observed [23], but indirectly confirmed what was observed in experimental studies [15].

Milk lysozyme showed large variations during the observation period, without a definite trend. The influence of different herd IMI prevalence on this result could be hypothesised. Indeed, the role of the pathogens in eliciting different levels of immune response has been demonstrated [14, 22]. However, in our study, the differences observed in immune parameters were not statistically associated with the different bacteria isolated (data not shown).

Overall, these data confirmed the results of a previous study on blood parameters [23], suggesting that the level of non-specific immune parameters could be influenced, in addition to heath status, by management and genetics. These latter aspects need more targeted studies to confirm this hypothesis and to define the role of bacteria.

The comparison of immune parameters in blood and milk confirmed that the immune response at the milk level could be different from what is observed at the blood level, as suggested by [15]. Indeed, NAG activity was higher in milk than in the blood in the first two weeks after calving. Moreover, samples from infected quarters showed significantly higher NAG activity in comparison with healthy ones, suggesting an immune response by milk cells. Gammaglobulin behaviour confirmed these observations; indeed, blood $\gamma \mathrm{G}$ showed a progressive increase, especially in infected 
cows, while it was the opposite for milk $\gamma \mathrm{G}$. In infected animals, we observed an increase of blood $\gamma \mathrm{G}$ at 45 DIM, but not at the milk level. A possible explanation of this result is supplied by the increase of ALB in milk at 21 and 28 DIM, and the parallel decrease in blood. This observation suggests the opening of the milk-blood barrier, due to the release of mediators of inflammation, and the consequent stimulation of $\gamma \mathrm{G}$ production [14].

Lactoglobulin, the major whey protein of ruminants, showed significant differences in IMI quarters in comparison with negative ones. The functions of this protein are still unclear [11], but our data support the hypothesis that LG could be involved in preventing bacterial adhesion as hypothesised at the gut level $[11,18,19]$. If the protein acts in the same way at the udder level, its lower concentration could ease the outcome of bacterial infection.

Lactoglobulin is synthesised at the udder level; therefore the differences observed in milk from healthy and IMI animals, but not in blood globulins was not unexpected. However, the low levels observed in blood globulins during the first month of lactation support the presence of an impairment of immune defences as described [13, 23].

We did not observe a significant decrease in RB in milk PMN post-calving, as happens in blood PMN [23]. However, the RB values from infected quarters at $7 \mathrm{~d}$ were lower, even if not significantly, than the values observed during the last part of the follow-up period. Milk PMN from healthy cows showed very low RB levels in all samples, while the values from the infected quarters were significantly higher. This could be explained by the presence of activated PMN as suggested by Mehrzad et al. [15]. The release of mediators of inflammation at the udder level could induce a depletion of activated blood PMN to milk $[14,15]$ and therefore the decrease of RB in blood PMN from infected animals, after the first month of lactation.
These data suggest that a decrease in non-specific immune defences can be observed during the periparturient period at the milk level, as expected [9, 12, 13, 15], but to a lesser extent in comparison to what is observed at the blood level in the same cow [23]. Cellular enzymes and RB showed different values in comparison to blood ones, but a significant decrease in the first samplings after calving could not be demonstrated. The interaction with herds and with IMI prevalence suggests that the udder immune response could be influenced both by the cow's immune status and by external factors such as pathogens and management. Therefore, the reduction in immune defences, particularly in heifers, is not unavoidable, as already suggested under experimental conditions [14], and the methods to particularly boost PMN activity should be investigated.

\section{REFERENCES}

[1] Barker A.R., Schrick F.N., Lewis M.J., Dowlen H.H., Oliver S.P., Influence of clinical mastitis during early lactation on reproductive performance of Jersey cows, J. Dairy Sci. 81 (1998) 1285-1290.

[2] Carlson G., Kaneko J.J., Isolation of leukocytes from bovine peripheral blood, Proc. Soc. Exp. Biol. Med. 142 (1973) 736-741.

[3] Craven N., Williams M.R., Defences of the bovine mammary gland against infections and prospects for their enhancement, Vet. Immunol. Immunopathol. 10 (1985) 71-127.

[4] Curtis C.R., Erb H.N., Sniffen C.J., Smith R.D., Kronfeld D.S., Path analysis of dry period nutrition, postpartum metabolic and reproductive disorders, and mastitis in Holstein cows, J. Dairy Sci. 68 (1985) 2347-2359.

[5] Dosogne H., Burvenich C., Freeman A.E., Kehrli M.E. Jr., Detilleux J.C., Sulon J., Beckers J.F., Hoeben D., Pregnancy-associated glycoprotein and decreased polymorphonuclear leukocyte function in early post-partum dairy cows, Vet. Immunol. Immunopathol. 67 (1999) 47-54.

[6] Hatcher L., Stepanski E.J., A step-by-step approach to using SAS system for univariate and multivariate statistics, SAS Institute Inc., Cary, 1994, 552 p. 
[7] Ingvartsen K.L., Dewhurst R.J., Friggens N.C., On the relationship between lactational performance and health: is it yield or metabolic imbalance that cause production diseases in dairy cattle? A position paper, Livest. Prod. Sci. 83 (2003) 277-308.

[8] Kehrli M.E. Jr., Goff J.P., Periparturient hypocalcemia in cows: effects on peripheral blood neutrophil and lymphocyte function, J. Dairy Sci. 72 (1989) 1188-1196.

[9] Kehrli M.E., Nonnecke B.J., Roth J.A., Alterations in bovine neutrophil function during the periparturient period, Am. J. Vet. Res. 50 (1989) 207-214.

[10] Kitchen B.J., Middleton G., Salmon M., Bovine milk $\mathrm{N}$-acetyl-beta-D-glucosaminidase and its significance in the detection of abnormal udder secretions, J. Dairy Res. 45 (1978) 15-20.

[11] Kontopidis G., Holt C., Sawyer L., Invited review: $\beta$-lactoglobulin: binding properties, structure, and function, J. Dairy Sci. 87 (2004) 785-796.

[12] Mallard B.A., Dekkers J.C., Ireland M.J., Leslie K.E., Sharif S., Van Kampen C.L., Wagter L., Wilkie B.N., Alteration in immune responsiveness during the peripartum period and its ramification on dairy cow and calf health, J. Dairy Sci. 81 (1998) 585-595.

[13] Mehrzad J., Dosogne H., Meyer E., Heyneman R., Burvenich C., Respiratory burst activity of blood and milk neutrophils in dairy cows during different stages of lactation, J. Dairy Res. 68 (2001) 399-415.

[14] Mehrzad J., Duchateau L., Burvenich C., Viability of milk neutrophils and severity of bovine coliform mastitis, J. Dairy Sci. 87 (2004) 4150-4162.

[15] Mehrzad J., Duchateau L., Pyorala S., Burvenich C., Blood and milk chemiluminescence and viability in primiparous and pluriparous dairy cows during late pregnancy, around parturition and early lactation, J. Dairy Sci. 85 (2002) 3268-3276.

[16] Metcalf J.A., Gallin J.I., Nauseef W.M., Root R.K., Laboratory manual of neutrophil function, Raven Press, New York, 1986, 191 p.
[17] National Mastitis Council, Laboratory handbook on bovine mastitis, revised ed., National Mastitis Council Inc., Madison, 1999, 222 p.

[18] Ouwehand A., Salminen S., Adhesion inhibitory activity of beta-lactoglobulin isolated from infant formulae, Acta Paediatr. 87 (1998) 491-493.

[19] Ouwehand A., Conway P., Salminen S., Inhibition of S-fimbria-mediated adhesion to human ileostomy glycoproteins by a protein isolated from bovine colostrum, Infect. Immun. 63 (1995) 4917-4920.

[20]Paape M.J., Mehrzad J., Zhao X., Detilleux J., Burvenich C., Defense of the bovine mammary gland by polymorphonuclear neutrophil leukocytes, J. Mammary Gland Biol. Neoplasia 7 (2002) 109-121.

[21] Paape M.J., Bannerman D.D., Zhao X., Lee J.W., The bovine neutrophils: structure and function in blood and milk, Vet. Res. 34 (2003) 597-628.

[22] Piccinini R., Bronzo V., Moroni P., Luzzago C., Zecconi A., Study on the relationship between milk immune factors and Staphylococcus aureus intramammary infections in dairy cows, J. Dairy Res. 66 (1999) 501-510.

[23] Piccinini R., Binda E., Belotti M., Casirani G., Zecconi A., The evaluation of non-specific immune status of heifers in field conditions during the periparturient period, Vet. Res. 35 (2004) 539-550.

[24] Pyorala S., Indicators of inflammation in the diagnosis of mastitis, Vet. Res. 34 (2003) 565-578.

[25] Rainard P., The complement in milk and defence of the bovine mammary gland against infections, Vet. Res. 34 (2003) 647-670.

[26] SAS/STAT, User's guide Version 8, SAS Institute Inc., Cary, 2000.

[27] Sordillo L., Streicher K.L., Mammary gland immunity and mastitis susceptibility, J. Mammary Gland Biol. Neoplasia 7 (2002) 135-146.

[28] SPSS, Statistical Package for Social Science, SPSS Advanced Statistics, SPSS Inc., Chicago, USA, 2002.

[29] Zecconi A., Smith K.L., Ruminant Mammary Gland Immunity, Bruxelles FIL-IDF, 2003, $128 \mathrm{p}$. 